\section{Discussion}

Early surgical intervention is critical for the treatment of acute aortic dissection and acute aortic valve endocarditis, because the mortality increases from the onset of symptoms. ${ }^{2}$ Diagnostic imaging, however, including CT, echocardiography, and coronary angiography, along with preparation for operative correction, usually takes longer than 4 hours, increasing the patient's risk. ${ }^{1}$ Although surgical repair should only be performed after coronary diagnostic imaging to avoid ischemic complications, coronary angiography is often a high-risk procedure for these patients. ${ }^{4}$

To circumvent this problem, we propose a simplified approach involving intraoperative angiography. This diagnostic tool was initially used to evaluate the grafts after coronary artery bypass grafting. ${ }^{5}$ This method showed a high accuracy in the identification of coronary lesions without adverse effects on either the cardiac function or histologic appearance of the coronary arteries. ${ }^{3,4}$ Multislice CT could be an alternative diagnostic tool for the preoperative screening of coronary disease. CT presents some limitations relative to intraoperative angiography, however, such as 2-fold higher radiation doses (approximately $34 \mathrm{mGy}$ versus approximately $80 \mathrm{mGy}$ ) and 10-fold higher contrast medium consumption (about $10 \mathrm{~mL}$ iopromide vs about $100 \mathrm{~mL}$ ). This difference may be of relevance, especially for patients with aortic valve endocarditis and impaired renal function.
In our patients, intraoperative angiography allowed us to detect coronary anomalies that could be surgically corrected in 2 of 7 cases. In our opinion, aortic root angiography may reliably demonstrate coronary artery lesions in patients who undergo heart surgery without preoperative catheterization.

\section{References}

1. Rizzo RJ, Aranki SF, Aklog L, Couper GS, Adams DH, Collins JJ, et al. Rapid noninvasive diagnosis and surgical repair of acute ascending aortic dissection. Improved survival with less angiography. J Thorac Cardiovasc Surg. 1994;108:567-74.

2. Shamsham F, Safi AM, Pomerenko I, Salciccioli L, Feit A, Clark LT, et al. Fatal left main coronary artery embolism from aortic valve endocarditis following cardiac catheterization. Catheter Cardiovasc Interv. 2000;50: 74-7.

3. Israel DH, Sharma SK, Ambrose JA, Ergin MA, Griepp RR. Cardiac catheterization and selective coronary angiography in ascending aortic aneurysm or dissection. Cathet Cardiovasc Diagn. 1994;32: 232-7.

4. Iida H, Lust RM, Spence PA, Sun YS, Pollock SB, Wheeler WS, et al. Feasibility of intraoperative aortic root angiography in the identification of critical coronary lesions. J Invest Surg. 1991;4:23-30.

5. Goldstein JA, Laster SB, Ferguson TB. Feasibility of intraoperative coronary angiography during hypothermic cardioplegic arrest. Ann Thorac Surg. 1994;57:1597-604.

\title{
Novel use of an aortic endograft in the closure of a Fontan circuit leak
}

\author{
Sanjeev Pradhan, MD, ${ }^{a}$ Bart E. Muhs, MD, PhD, ${ }^{a}$ John T. Fahey, MD, ${ }^{\mathrm{b}}$ and Jeremy D. Asnes, MD, ${ }^{\mathrm{b}}$ New Haven, Connecticut
}

U nintended residual interatrial communications or baffle leaks after the lateral tunnel Fontan operation have been well described. ${ }^{1}$ Such unintended communications have the potential to result in hypoxemia, cyanosis, exercise intolerance, and paradoxical embolization. ${ }^{2}$ Surgical eradication of these leaks has the attendant risks of reoperative sternotomy and cardiopulmonary bypass. Therefore, transcatheter approaches are now commonly used. No ideal device exists for this task. Gian-

From the Sections of Vascular Surgery, ${ }^{\mathrm{a}}$ and Pediatric Cardiology, ${ }^{\mathrm{b}}$ Yale University School of Medicine, New Haven, Connecticut.

Received for publication Oct 30, 2007; accepted for publication Feb 1, 2008.

Address for reprints: Jeremy D. Asnes, MD, Section of Pediatric Cardiology, Yale University School of Medicine, 333 Cedar Street, PO Box 208064, New Haven, CT 06520-8064 (E-mail: Jeremy.Asnes@yale.edu).

J Thorac Cardiovasc Surg 2008;136:793-5

$0022-5223 / \$ 34.00$

Copyright () 2008 by The American Association for Thoracic Surgery doi:10.1016/j.jtcvs.2008.02.074 turco coils (Cook Medical, Bloomington, Ind), Amplatzer septal occluders (AGA Medical, Plymouth, Minn), and CardioSEAL VSD occluders (NMT Medical, Boston, Mass) have been used with varying degrees of success. These devices often prove ineffective because of their inability to conform to the complex atrial anatomy. Balloon-expandable covered stents have been used to exclude leaks and intentional fenestrations with good success. ${ }^{3}$ However, balloonexpandable covered stents of sufficient size are not available in the United States. We describe the novel use of a commercially available adult-size, self-expanding aortic stent graft to seal a large, symptomatic Fontan baffle leak.

\section{Clinical Summary}

A 15-year-old male with dextrocardia, bilateral superior vena cavae, common atrium, and unbalanced atrioventricular canal defect had undergone multiple cardiothoracic surgeries culminating in a fenestrated lateral tunnel Fontan. He presented with exercise intolerance. Exercise testing demonstrated resting saturations of $91 \%$ to $96 \%$. Saturations decreased to $63 \%$ at peak exercise. Cardiac catheterization demonstrated right-to-left shunting (Qp:Qs 0.7) via both the fenestration and a large baffle leak. The baffle leak could not be 

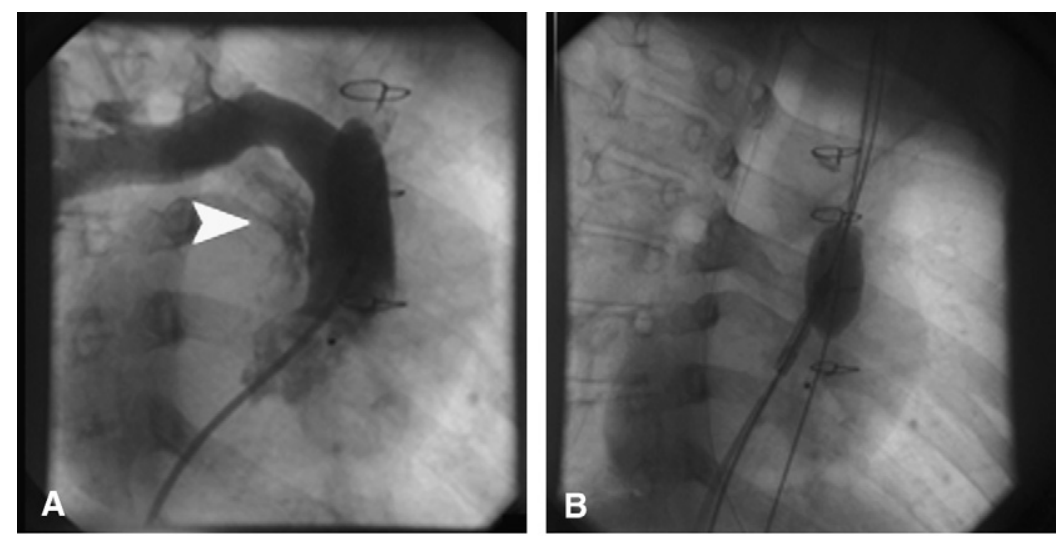

Figure 1. A, Superior anterior baffle leak (white arrow) in patient with dextrocardia. B, Sizing balIoon is used to occlude the left PA. C, Stent can be seen deployed across the baffle leak (white arrow). D, Final angiography demonstrates successful closure of the baffle leak.
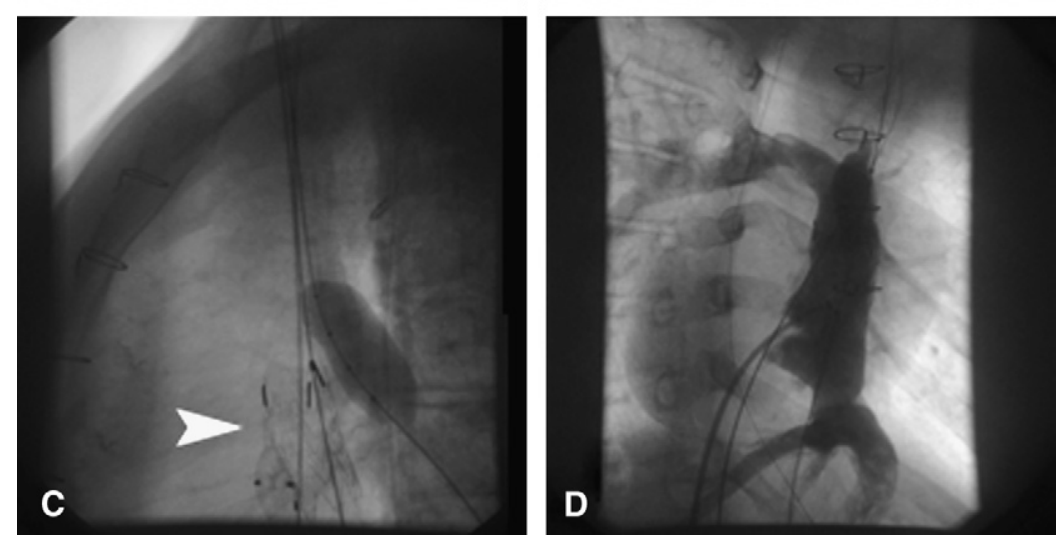
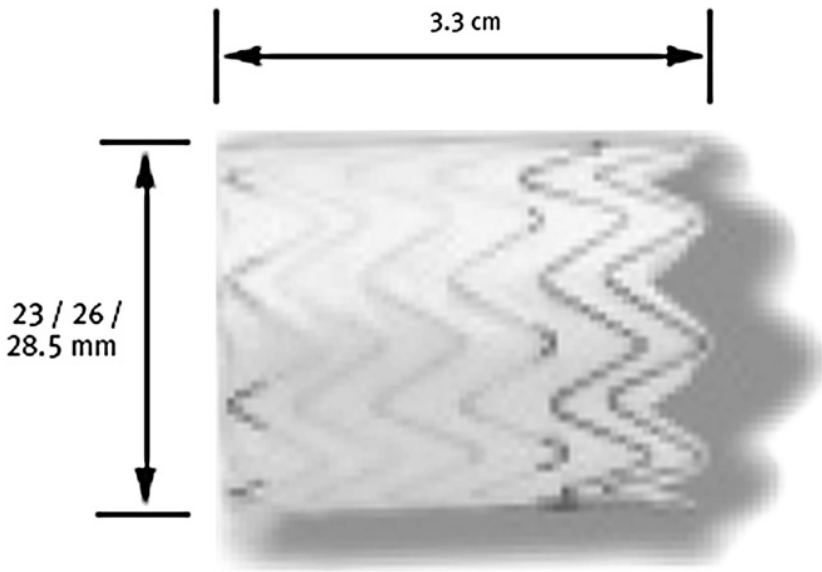

Figure 2. Aortic extender stent graft cuff (WL Gore and Associates, Flagstaff, Ariz).

crossed and was left untreated. The fenestration was closed with a 4mm Amplatzer septal occluder.

Despite fenestration occlusion, the patient continued to have significant exercise-induced desaturation. Reintervention using an aortic stent graft was planned. Bilateral common femoral veins and the left internal jugular vein were accessed. Angiography demonstrated a large leak at the superior anterior suture line of the Fontan baffle (Figure 1, A). The baffle at this level measured $19 \mathrm{~mm}$ with a 2$\mathrm{cm}$ proximal landing zone. An aortic extender cuff $23 \mathrm{~mm}$ in diameter by $33 \mathrm{~mm}$ in length (WL Gore and Associates; Flagstaff, Ariz) was selected (Figure 2). The device, normally delivered via an $18 \mathrm{~F}$ sheath, was delivered through a $16 \mathrm{~F}$ sheath (Figure 1,C). An 18-mm sizing balloon (Numed Inc, Hopkinton, NY) was positioned in the left pulmonary artery (PA) via the left internal jugular vein and inflated during stent deployment to prevent forward migration of the stent and inadvertent PA occlusion (Figure 1, B). After deployment, a compliant CODA balloon (Cook Medical, Bloomington, Ind) was used to angioplasty the stent, ensuring good wall apposition. Final angiography demonstrated good stent placement with no leak (Figure $1, D)$. Sheaths were removed and hemostasis was obtained using direct manual pressure. The patient was discharged within 48 hours on warfarin with a goal international normalized ratio of 2 .

Cardiac magnetic resonance imaging 2 months after stent placement demonstrated good stent apposition, no baffle distortion, and no residual shunt. During exercise stress testing 4 months after stent placement, the baseline saturation was $99 \%$ and the saturation at peak exercise was $98 \%$.

\section{Discussion}

We demonstrate the successful use of a commercially available aortic stent graft in the repair of a lateral tunnel Fontan baffle leak. The GORE (WL Gore and Associates) aortic extender cuff we used is constructed of expanded polytetrafluoroethylene 
(ePTFE) with an outer self-expanding Nitinol support structure. The aortic extender cuff is an adjunctive stent graft used for treatment of infrarenal abdominal aortic aneurysms demonstrating a type I (proximal sealing zone) endoleak. The exterior scaffolding confers flexibility and durability to the device, and the ePTFE provides the lumen with a smooth, nonthrombogenic surface. Although no published data exist, we believe that having the scaffolding isolated behind the ePTFE may help reduce the risk of thrombus formation. Endografts offer several advantages over other transcatheter devices: The target lesion does not need to be crossed; multiple leaks can be occluded with a single device; minimal proximal and distal landing zones are needed; and the devices conform well to the complex anatomy. These devices are available in a wide array of sizes and configurations that allow endovascular treatment to be individually tailored to a particular patient's anatomy. Self-expanding endografts may "jump" slightly during expansion. We inflated a sizing balloon in the left PA during stent deployment to prevent migration of the stent across the PA origins. We selected the more caudal left PA to ensure protection of both the left and right PA ostia. Post-stent placement balloon angioplasty was used to ensure apposition to the baffle wall. The major limitation to using endografts in the pediatric population is the need for an large introducer sheaths. We were able to deploy this particular endograft using a $16 \mathrm{~F}$ sheath, which may help to expand applicability.

\section{Conclusions}

Follow-up imaging demonstrated stable stent position and configuration with no demonstrable leak after 2 months. Saturations remained $98 \%$ during exercise testing 4 months after intervention.

\section{References}

1. Hsu HS, Nykanen DG, Williams WG, Freedom RM, Benson LN. Right to left interatrial communications after the modified Fontan procedure: identification and management with transcatheter occlusion. Br Heart J. 1995; 74:548-52.

2. Quinones JA, Deleon SY, Bell TJ, Cetta F, Moffa SM, Freeman JE, et al. Fenestrated Fontan procedure: evolution of technique and occurrence of paradoxical embolism. Pediatr Cardiol. 1997;18:218-21.

3. Marini D, Boudjemline Y, Agnoletti G. Closure of extra-cardiac Fontan fenestration by using the covered Cheatham Platinum stent. Catheter Cardiovasc Interv. 2007;69:1003-6. 